\title{
Queuing Theory Model of the Optimal Taxi Quantity
}

\section{Xiaolei Zhang}

School of North China Electric Power University, Baoding 071000, China;

837761034@qq.com

Keywords: Queuing theory, Multi-objective optimization, Optimal taxi quantity

\begin{abstract}
The major assumption is that the total number of cabs in a city should meet two requirements:

a) the average customer waiting time is $\leqslant 15$ minutes.

b) less than $10 \%$ of customers end up waiting more than 25 minutes.

Now we take a town named Ithaca as an example to work out the optimal taxi quantity. We establish the model of passengers waiting, to research what is the total number of cabs needed to serve the town and meet the two requirements. Passengers waiting for a taxi can be thought as the process of queuing up and waiting for service, in other words, we can use queuing theory to solve the problem.
\end{abstract}

\section{Introduction}

The population of the town is approximately 30015[1] and the number of students is 21593(states from the official website of the Cornell university). Though many of the people here own their private cars, there still some people (such as the students) go out with taxis. Thus, solving the problem about the taxi quantity makes sense.

Our mathematical model is based on the establishment of the above-described problem. We construct a model based on the queuing theory to work out the optimal taxi quantity. The point is that all of taxis can be seen a whole service platform. In the whole process the sum of passengers serviced by taxis is the number of person serviced by the platform once time.

\section{The queuing theory model}

\section{Model assumptions}

-In unit time(in one hour), the arrival of the passengers satisfies the Poisson distribution[2] and the interval of time of the two cabs satisfies an index distribution.

-This service system obeys the principle "First come first service"

- When those passenger who reached earlier get on the cab, the other passengers choose to wait until he accepts the service.

- A cab loads two passengers on average at every turn.

- The customers reach the platform one by one. Customers are independent of each other.

\section{Terminology and Definitions}

Table 1. Terminology and definitions

\begin{tabular}{cl}
\hline Symbol & Meaning \\
\hline$P$ & The intensity of the service. \\
$L_{S}$ & Team length \\
$L_{q}$ & The average team length \\
& The average team length subtract the \\
& intensity of the service \\
& Probability distribution of the team \\
& length $(N)$ after the system reaches \\
& the equilibrium state.
\end{tabular}




$\begin{array}{cl}B & \text { The average work time } \\ W_{q} & \text { The average waiting time } \\ \lambda & \begin{array}{l}\text { The average number of customers } \\ \text { reached in one hour }\end{array} \\ \mu & \begin{array}{l}\text { The average service rate, the number of } \\ \text { the customers who can be carried in the } \\ \text { unit of time } \\ 1 / \mu\end{array} \\ T_{0} & \begin{array}{l}\text { Mean time between every two customers } \\ \text { arrived }\end{array} \\ & \text { One taxi's average service time once time } \\ T & \begin{array}{l}\text { The average no-load rate } \\ \text { The time of passengers staying in the } \\ \text { system(the time waiting taxi+the time of } \\ \text { accept service) }\end{array}\end{array}$

\section{The process of calculation}

All of the taxi in Ithaca can be seen a service platform and all of the passengers in here queues and waits service, which satisfy the model of single service desk.[3]

There is a time slot, which is assumed as $[t, t+1]$.The next ,we analyze the average waiting time of passengers in this process.

We assume that the whole Ithaca has $\mathrm{Y}$ taxi and per hour one taxi can carry a group of passengers. the number of people of each group is random. To analyze easily, we assume each group of passengers has two persons.

$$
\mu=1 / T_{0} \times Y \times(1-K) \times 2
$$

According to the website of the Ithaca, we know that the population $M$ of this town is 36522.54 .

On the basis of official statistics,we use Weighted average method and get that the number of the people go out at the rush hour account for 20 percent.

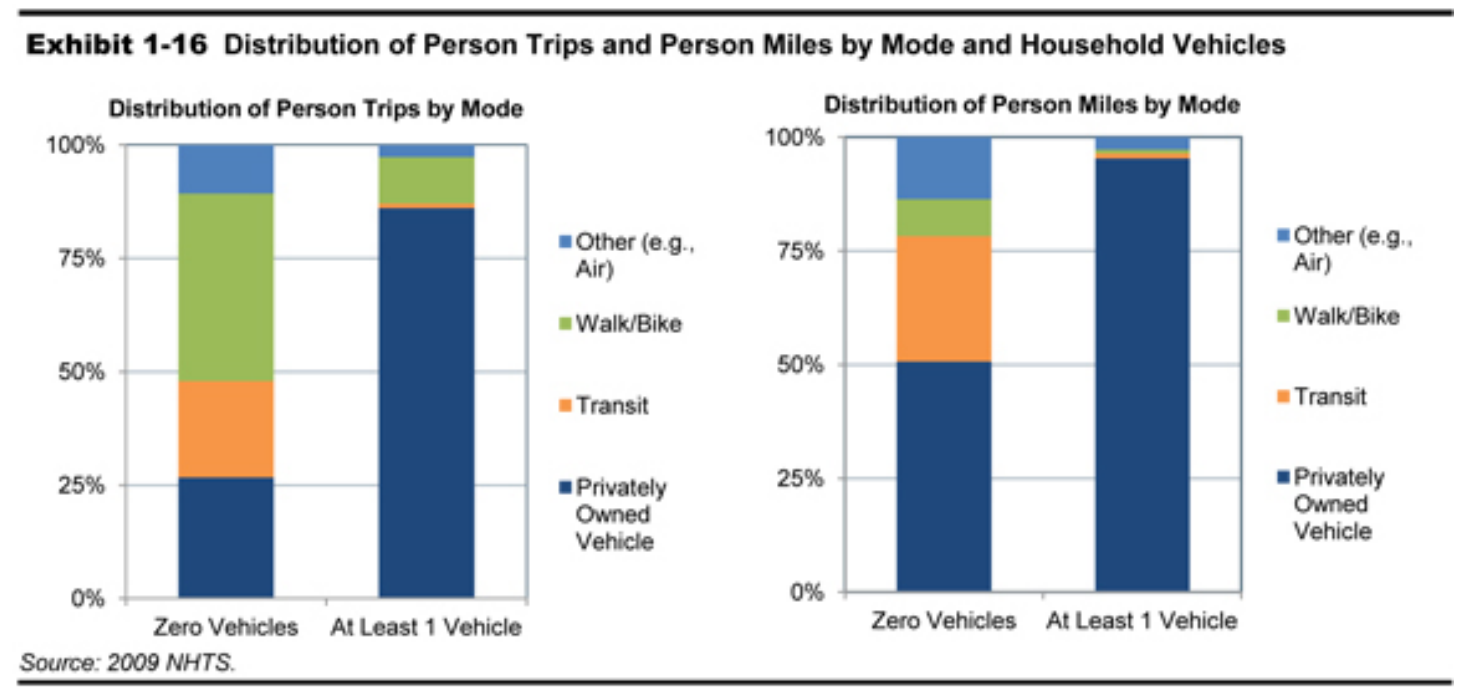

Figure 1 (source:2009 NHTS)

We can see there are 25 percent of the total people who need go out choose to travel with a cab.

We can make reasonable assumptions that the cabs work 12 hours during a day and the number of the people who need to take a taxi per hour distribute evenly.During this period of time, people who need to go out take account of 60 percent of the total population and every people go out 1.5 times a day. So we can get $\lambda$ :

$$
\lambda=\mathrm{M} / 12 \cdot 60 \% \cdot 1.5 \cdot 25 \%=684
$$


The average service length is:

$$
60 \div 15=4
$$

Supposed the speed of the cab is 25 miles per hour (according to the New Yore politics)[4],we use 20 miles per hour as the average speed, the average service time is:

$$
T_{0}=4 \div 20=0.2
$$

Taking $K$ into account, it is reasonable if we set $K$ to $35 \%$, combined with the outstanding experiences of taxi operation in developed countries.

$$
\mu=\frac{1}{T_{0}} \times Y \times(1-K) \times 2=3 Y
$$

Easy to get

$$
\mathrm{P}=\lambda / \mu
$$

Assume $\mathrm{P}<1$ in case of that the queue lines up to infinity. According to the queuing theory, we can get

$$
P_{n}=P^{n} P_{0}, n=1,2,3 \ldots \ldots
$$

Among the fifth formula

$$
P_{0}=\frac{1}{1+\sum_{n=1}^{n} P_{n}}=\left(\sum_{n=1}^{n} P^{n}\right)^{-1}=(1 /(1-P))^{-1}=1-P
$$

After the reduction we can get

$$
P_{n}=(1-P) P^{n}
$$

We can get the average team length

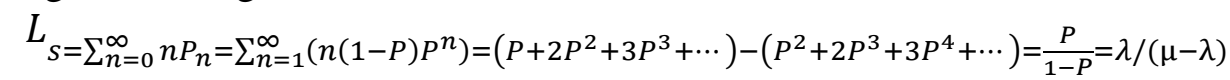

$$
\begin{aligned}
& L_{q}=L_{s}-P=\lambda^{2} /[\mu(\mu-\lambda)] \\
& W_{q}=\frac{L_{q}}{\lambda}=\lambda /[\mu /(\mu-\lambda)] \leq 15 / 60
\end{aligned}
$$

Then we combine the second, the third and the tenth formula. Finally we can figure out: $Y \geq$ 229.3256

\section{Conclusion}

Using the queuing theory model, we finally work out that the optimal taxi quantity is 230 . The conclusion squares with the fact roughly. That is, our model is reliable.

\section{Reference}

[1]:http://www.city-data.com/county/Tompkins_County-NY.html

[2]:AC Cameron, PK Trivedi - Journal of Econometrics, 1990 - Elsevier

[3]:Frolkin AV ,van der Wyck FDW ,Burgess S. Theme-park queuing systems. The UMAP Jouranal,2004,25(3) :301-318

[4]: New York Vehicle and Traffic Law 